\title{
NATURA MATERIALITER SPECTATA NATURALEZA, FINALIDAD Y ORGANISMO EN LA CRÍTICA DE LA FACULTAD DE JUZGAR DE KANT**
}

\author{
Eduardo A. Molina Cantó \\ Universidad Alberto Hurtado \\ emolina@uahurtado.cl
}

\begin{abstract}
Resumen
Uno de los problemas que se le presentan a Kant en la Crítica de la facultad de juzgar es el de la aptitud de la naturaleza en su diversidad particular para ser conformada por las leyes del entendimiento. En este contexto, Kant define los conceptos de naturaleza, materia y finalidad de una manera que antes no había tenido cabida en su sistema, y postula la idea de una técnica o arte de la naturaleza. En este artículo se analiza y discute cómo Kant aborda esto, haciendo hincapié en el papel que juega el principio de la conformidad a fin en el marco de una naciente ciencia de los seres vivos.
\end{abstract}

Palabras clave: Kant, Crítica de la facultad de juzgar, teleología, explicación mecánica, materia, organismo.

\section{Abstract}

One of the problems for Kant in the Critique of Judgment is the suitability of nature's particular diversity to the laws of the understanding. In this context, Kant characterizes the concepts of nature, matter and purposiveness in a novel fashion, putting forward the idea of an art or technique of nature. This article considers this new Kantian approach emphasizing the role played by the principle of purposiveness in a context in which a new science of living beings is emerging.

KEYWORDS: Kant, Critique of judgment, teleology, mechanical explanation, matter, organism.

D1 En un enigmático pasaje del $§ 65$ de la Crítica de la facultad de juzgar, Kant resume algunos de los problemas centrales que se analizan en esa obra, de la siguiente manera:

Este trabajo fue realizado en el marco del proyecto de investigación Fondecyt $\mathrm{N}^{\mathrm{o}}$ 1080362. 
"Es muy poco lo que se dice de la naturaleza y de su facultad en los productos orgánicos cuando a ésta se la llama un análogo del arte, pues en tal caso se piensa al artista (un ser racional) fuera de ella. [...] Más se aproxima uno quizás a esta inescrutable propiedad si se la llama análogo de la vida; pero en tal caso hay que dotar a la materia como simple materia con una propiedad (hilozoísmo) que contraría su esencia, o bien asociarle un principio ajeno que esté en comunidad con ella (un alma); [...]. Hablando con exactitud, la organización de la naturaleza no tiene, pues, nada análogo con alguna causalidad que conozcamos" $(K U \S 65$, AA V, 374-375; tr., pp. 305-306).

Esta relación compleja entre los conceptos de naturaleza, materia, arte y vida sirve para destacar uno de los hilos argumentativos que recorre toda esta última Crítica de Kant y que representa un avance importante, a mi juicio, al interior del sistema crítico. Por cierto, la relación entre estos conceptos puede rastrearse desde muy temprano en su obra, pero será recién en el libro de 1790 donde Kant abordará derechamente el problema que se esconde aquí, a la luz de la facultad de juzgar reflexionante y de su principio original: el principio de la conformidad a fin. Intentaré mostrar luego que es precisamente el descubrimiento de este principio de la reflexión lo que hizo que Kant volviera sobre un problema que, en un comienzo, no era más que un enigma para Kant y para casi toda la filosofía de su época, a saber, el hecho de que las leyes de la mecánica newtoniana no parecían poder abarcar y explicar el abigarrado mundo de los seres vivos.

Es, pues, en este contexto donde Kant se plantea tempranamente el problema de conciliar la explicación mecánica de la naturaleza con la explicación teleológica. En una época en que el preformacionismo estaba declinando y surgían por doquier diversas teorías epigenetistas, Kant irá madurando su posición hasta exponerla recién de manera completa en su tercera Crítica. Todo indica, por cierto, que Kant desconfió siempre de la doctrina preformacionista, defendida entre los filósofos especialmente por Leibniz, dada su apelación metafísica a un Dios artífice, pero su adhesión al epigenetismo de Buffon y Blumenbach también fue cautelosa, como han mostrado Lenoir (1980; 1982, p. 23 ss.) y McLaughlin (1990, p. 8 ss.).

A modo de ilustración del planteamiento temprano de Kant al respecto, recuérdese el siguiente pasaje de su Teoría del cielo, donde, primeramente, en defensa de una explicación mecánica del origen del universo y en abierto reconocimiento a la tradición materialista de Demócrito y Epicuro, señala con entusiasmo:

"Me parece que aquí se puede decir en cierta manera sin temeridad: dadme materia y os construiré con ella un mundo, es decir, dadme materia y os mostraré cómo un mundo ha de nacer de ella" (Theorie des Himmels, AA I, 229-230; tr., p. 20.)

Pero añade enseguida su único reparo:

"En cambio, ¿podemos jactarnos de esta ventaja respecto de las más humildes plantas o insectos? ¿Podemos decir: dadme materia y os mostraré cómo se produce una oruga? ¿No quedamos paralizados desde el primer paso, por ignorar 
la naturaleza íntima del objeto y las complicadas diversidades que encierra? No debe, pues, extrañar a nadie si me atrevo a decir que la formación de todos los cuerpos siderales, la causa de sus movimientos, en fin, el origen de toda la actual constitución del universo podrá ser comprendido con mayor facilidad que el nacimiento de una sola hierba o el de una oruga explicado exacta y completamente por meras causas mecánicas" (Theorie des Himmels, AA I, 230; tr., pp. 20-21).

Esta reflexión se repetirá unos años después, en uno de los escritos más importantes del período precrítico, El único fundamento posible de una demostración de la existencia de Dios (1763), donde, luego de reconocer también la necesidad de explicar los fenómenos de la naturaleza de acuerdo a las leyes generales de la ciencia newtoniana, señala:

"Sin embargo, la naturaleza es rica también en un género distinto de producciones en las que la filosofía, cuando reflexiona sobre el modo como se han originado, se ve precisada a abandonar la vía precedente. Pues se muestra en ella un gran arte y una asociación de elementos contingente y realizada por una elección libre encaminada a ciertos propósitos, al propio tiempo que aparece el principio de una ley natural especial que pertenece al orden artístico de la naturaleza" (Beweisgrund, AA II, 114; tr., p. 109).

Veamos entonces cómo se plantea este problema en la segunda parte de la Crítica de la facultad de juzgar.

Kant sostiene que el principio que gobierna nuestra reflexión sobre la naturaleza y que nos obliga a explicar todos los sucesos (en lo que tienen de particular) en términos puramente mecánicos, no es otra cosa que una "máxima" de nuestra facultad de juzgar reflexionante (cf. $K U \S 70, \mathrm{AA} \mathrm{V,} 386$ ss.; tr., p. 317 ss.). En este sentido, Kant llega a afirmar que la idea de una aplicación irrestricta del principio de la causalidad natural (expuesto con radicalidad en la segunda analogía de la experiencia de la Crítica de la razón pura, como principio constitutivo de nuestro conocimiento de la naturaleza y al que nada, por tanto, puede sustraerse), no es más que una máxima "regulativa" que se expresa en la siguiente fórmula: "toda generación de cosas materiales y de sus formas tiene que ser juzgada como posible según leyes meramente mecánicas" ( $§ 70$, AA V, 387; tr., p. 316); esto no quiere decir, sin embargo, que las cosas particulares solo sean posibles de acuerdo a tales leyes mecánicas y que no pueda haber otro tipo de causalidad o nexo entre las cosas que la conexión causal meramente mecánica. Por el contrario, mostraré ahora que en ciertos casos precisos, según Kant, se requiere una máxima distinta, que es precisamente la de la conformidad a fin (Zweckmässigkeit), o finalidad de la naturaleza.

Nunca podrá haber, dice Kant en una frase memorable, un "Newton [...] de una brizna de hierba" ( $K U \S 75$, AA V, 400; tr., p. 329). Para dar cuenta de los fenómenos vitales, incluidos los humanos, pero también todos los procesos biológicos de cualquier especie, debemos reflexionar de una manera diferente y, según Kant, así lo hacemos de hecho cada vez que experimentamos esos fenómenos en su particularidad. Debemos buscar los fines, el sentido y la orientación inmanente de tales 
manifestaciones, porque, en estos casos, el sujeto no experimenta meras relaciones causales mecánicas, sino series organizadas de procesos y eventos, fines inmanentes, pautas de orientación y también funciones biológicas. Por lo tanto, el principio que guía la reflexión sobre estas experiencias no es únicamente el mecánico-causal, sino, en términos de Kant, el principio de la conformidad a fin de la naturaleza. Con esto, se podría decir, Kant retoma, a contramano de una época donde solo imperan las causas eficientes, el aspecto teleológico de la reflexión sobre los seres vivos, en consonancia con la orientación aristotélica de la filosofía, por un lado, y en discusión con la crítica spinoziana a la finalidad en cuanto ignorantiae asylum, por otro.

Kant encara esta cuestión en la Dialéctica de la facultad de juzgar teleológica. Ahí, en efecto, el conflicto antitético ya no se establece entre la necesidad causal de la naturaleza y la posibilidad de la libertad, como en la tercera antinomia de la Dialéctica de la Crítica de la razón pura, ni entre la ley moral y la felicidad, como en la Crítica de la razón práctica, sino entre dos "máximas" igualmente necesarias de la reflexión a la hora de investigar y comprender la naturaleza en sus manifestaciones particulares. Según la tesis (primera máxima),

"toda generación (Erzeugung) de cosas materiales y de sus formas tiene que ser juzgada como posible según leyes meramente mecánicas" ( $K U \S 70, \mathrm{AA} \mathrm{V,} \mathrm{387;}$ tr., p. 316).

Según la antítesis (segunda máxima), en cambio,

“algunos productos (Produkte) de la naturaleza material no pueden ser juzgados como posibles según leyes meramente mecánicas (su enjuiciamiento requiere una ley de causalidad enteramente distinta, a saber, la de las causas finales)" ( $K U$ $\S 70$, AA V, 387; tr., pp. 316-317).

Ahora bien, como se trata de máximas de la facultad de juzgar reflexionante, argumenta entonces Kant, resulta claro que no puede haber contradicción alguna entre ambas si se recuerda que ellas solo prescriben el modo en que debemos necesariamente juzgar los acontecimientos de la naturaleza material, y reflexionar sobre ellos, sin determinar cómo son estos constitutivamente. Este punto es esencial para la presente argumentación y hay que entenderlo bien.

La primera máxima, en efecto, no dice que todo en la naturaleza sea únicamente posible con arreglo a leyes mecánicas y con exclusión de cualquier otro tipo de causalidad; solo dice que en todo caso particular debemos reflexionar de acuerdo con el principio del mecanismo e investigar de ese modo hasta donde nos sea posible. Pero si, a pesar de todos nuestros esfuerzos, no logramos encontrar una explicación mecánica que nos permita entender esos fenómenos particulares en su sentido más peculiar (o incluso a la naturaleza entera, como sistema), entonces podemos legítimamente adoptar la segunda máxima e indagar de acuerdo con el principio de la causalidad final. Con esto, pues, no se suprime en absoluto la primera máxima (que puede y debe continuar investigando en pos de nuevas conexiones mecánicas simultáneamente), sino que solo se nos dice que "para nosotros, en cuanto hombres", la explicación 
mecánica es limitada en su capacidad de llegar a término a la hora de atender a ciertos productos de la naturaleza $(K U \S 80, \mathrm{AA} \mathrm{V}, 417-418$; tr., p. 345). La reflexión teleológica puede equivocarse en la aplicación de su principio, por cierto, pero el punto aquí es únicamente que ambas máximas pueden coexistir sin estorbarse, según Kant.

Ahora bien, la clara conexión entre esta primera máxima y la segunda analogía de la experiencia establecida en la primera Crítica hace pensar que nos encontramos ahora ante una modificación significativa de la doctrina kantiana de la causalidad, lo que ha dado lugar a una larga discusión entre muchos comentaristas (cf. Breitenbach 2006; Ginsborg 2004; Watkins 2008). Se podría sostener, en efecto, que Kant ahora reconoce que el principio de la causalidad irrestricta de la naturaleza es en el fondo solo un principio regulativo de la facultad de juzgar (cf. Butts 1984, p. 272 ss.; Guyer 1992, p. 23 s.); pero es cierto que con esto la incoherencia del sistema crítico en su conjunto se haría patente, como ha mostrado Allison en su estudio de esta antinomia (1991).

En efecto, la legalidad del entendimiento sobre la naturaleza, a través del principio de causalidad, posee valor constitutivo, porque únicamente bajo esa legalidad son posibles los objetos de la experiencia. A mi entender, esta doctrina fundamental no varía esencialmente en la tercera Crítica. La modificación que Kant hace ahora tiene que ver solo con el problema de la aplicación de las leyes del entendimiento a los casos particulares y, según Kant, el problema de la aplicación es asunto de la facultad de juzgar, no del entendimiento.

Si se compara la máxima del mecanismo con la segunda analogía de la experiencia, se puede ver que la primera se plantea derechamente como un principio heurístico que guía la investigación de los fenómenos precisamente en sus leyes particulares, donde la experiencia nos presenta los fenómenos individuales en su más heterogénea variedad. Suponer que incluso ahí -en lo más contingente de nuestra experiencia y donde nada puede ser determinado a priori- es posible aplicar en concreto el principio de la causalidad mecánica, eso es lo que nos señala la máxima como un deber. La segunda analogía, en cambio, da las condiciones formales de un objeto en general, dejando a la experiencia misma averiguar qué cosa concreta es causa de tal otra.

El problema de fondo que descubre a este respecto Kant radica en que, para poder determinar los objetos desde un punto de vista formal, debe suponerse que la materia misma es desde un principio afín a nuestra dotación subjetiva (cf. Molina 2007; Zuckert 2007, p. 26 ss.). ¿Cómo entender, sin embargo, esta afinidad material de la naturaleza, esto es, la correspondencia entre una natura materialiter spectata y la natura formaliter spectata? Dice Kant en su introducción a la Crítica de la facultad de juzgar:

"Es, en efecto, perfectamente posible pensar que, no obstante toda la uniformidad de las cosas de la naturaleza según leyes universales, sin las cuales no tendría lugar en absoluto la forma de un conocimiento empírico en general, la diferencia específica de las leyes empíricas de la naturaleza, junto a sus efectos, podría ser tan grande, que para nuestro entendimiento fuese imposible descubrir 
en ella un orden aprehensible para dividir sus productos en géneros y especies, a fin de emplear los principios de definición y comprensión de uno también para la definición y conceptualización del otro, y hacernos, de un material tan embrollado para nosotros (en sentido propio, solo infinitamente diverso y no adecuado a nuestra fuerza de aprehensión), una experiencia coherente" (KU, Einleitung, AA V, 185; tr., p. 96).

¿Habrá que conjeturar, entonces, una armonía preestablecida entre nuestras almas y la naturaleza externa? ¿O un intelecto originario que haya diseñado la naturaleza de modo tal que se puedan cumplir en ella todos nuestros propósitos cognoscitivos? $¿ \mathrm{O}$, por el contrario, el mecanismo de la naturaleza es tan ciego y sin fundamento que no es posible encontrar en él ninguna finalidad, salvo la que inventa ilusoriamente el ser humano cuando desconoce las causas efectivas, como enseñaba agudamente Spinoza? Hay que reconocer que en este punto la crítica kantiana se enfrenta a la metafísica racionalista en el propio terreno de esta última. Kant encara aquí, en efecto, tanto la Teodicea leibniziana como la Ética naturalista de Spinoza, es decir, tanto la idea de un Dios racional que ordena todo de acuerdo a una armonía preestablecida, como la de un Dios-naturaleza que incluye todo en sí mismo, de manera necesaria de acuerdo a conexiones causales ${ }^{1}$. Y se puede decir a este respecto, me parece, lo mismo que Kant afirmaba sobre la posición del filósofo crítico en la Fundamentación:

"Vemos aquí, en efecto, cómo la filosofía está colocada en una posición bastante precaria, pues ha de mantenerse firme sin pender de nada que esté en el cielo ni apoyarse en nada que esté sobre la tierra" (GMS, AA IV, 425; tr., p. 99).

Para entender esto, recordemos ahora las fórmulas más generales del juicio teleológico, según Kant: "la naturaleza toma el camino más corto" (lex parsimoniae), "no hace nada en balde", "no da saltos en la diversidad de las formas" (lex continui in natura), "es rica en especies y, sin embargo, parsimoniosa en los géneros" (1. Einleitung $K U$, AA XX, 210; tr., p. 34; $K U$, Einleitung, AA V, 182; tr., p. 93). Se puede reconocer, me parece, que la tentación de interpretar estas fórmulas, que apuntan a cierta legalidad final de la naturaleza misma, como si esta estuviera guiada por una suerte de propósito inteligente, es ciertamente grande. Pero Kant intenta dar una explicación comprensiva de esto sin recurrir a algo que desborde la experiencia misma, aunque esto implique, precisamente, ampliar el concepto de experiencia que se había forjado a partir de las dos primeras críticas y, particularmente, de la primera.

1 La idea de una armonía preestablecida es tan fuerte en la época anterior a Kant, que incluso Hume apela a ella en un pasaje esencial de su Investigación sobre el conocimiento humano. Dice ahí Hume: “Aquí hay, pues, una especie de armonía preestablecida entre el curso de la naturaleza y la sucesión de nuestras ideas, y, aunque los poderes y las fuerzas por las que la primera es gobernada nos son totalmente desconocidos, de todas formas encontramos que nuestros pensamientos y representaciones han seguido la misma secuencia que las demás obras de la naturaleza" (S-B, 54-55; tr., p. 88). 
De acuerdo con lo planteado en las dos introducciones a la Crítica de la facultad de juzgar, el juicio teleológico, que reflexiona y juzga objetivamente sobre la naturaleza según el principio de la conformidad a fin, es, en cuanto a su uso, un juicio de conocimiento, orientado por tanto al interés teórico de la facultad de conocer (cf. 1 . Einleitung $K U$, AA XX, 221; tr., p. 43; $K U$, Vorrede, AA V, 169; tr., p. 81). Como se trata, sin embargo, de un juicio reflexionante y no de uno determinante, esta consideración objetiva de la naturaleza como realmente conforme a fin, solo se hace en vista de nuestras propias necesidades subjetivas de interpretación de la naturaleza. El juicio teleológico, por tanto, tiene que ver ante todo con el concepto que nos hacemos de la naturaleza, esto es, con una regla para reflexionar sobre los objetos de la naturaleza ${ }^{2}$.

En este sentido, Kant es consecuente al sostener que en último término es propiamente la facultad de juzgar la que procede técnicamente, al considerar la naturaleza como conforme a fin. Únicamente de manera derivada es posible considerar, entonces, que la naturaleza se comporta técnica o artísticamente, a saber, solo en la medida en que ella concuerda con esa reflexión y se deja describir conforme al principio de la finalidad (cf. 1. Einleitung $K U$, AA XX, p. 220; tr., p. 42). Dicho de otro modo, la analogía con el arte solo se impone cuando y porque reflexionamos sobre la capacidad productora y autoorganizadora de la naturaleza.

¿Cómo nace esta reflexión sobre una naturaleza artística, según Kant? En la experiencia teleológica -si se me permite la expresión-, algo debe sernos dado de modo tal que no podamos sino enjuiciarlo como conforme a fin, reconociendo por tanto que la explicación mecánica no es suficiente para dar cuenta de ese fenómeno particular en su sentido más propio. Pero en ningún caso, precisa Kant, podemos llegar a atribuirle una "intención" (Absicht) a la naturaleza (cf. 1. Einleitung $K U$, AA $\mathrm{XX}, 236$; tr., p. 56). A la pregunta anterior se debe agregar, pues, esta otra: ¿cómo entender la noción de una conformidad a fin sin intención?

A mi entender, para Kant, la idea de una naturaleza artística tiene su origen en la experiencia de lo bello natural, pues solo a partir de esta experiencia surge en el hombre este pensamiento: "que la naturaleza produjo esa belleza" ( $K U \S 42$, AA V, 299; tr., p. 209), es decir, la admiración por el hecho de que la naturaleza, espontáneamente, exprese en sus productos bellos una conformidad afín con nuestro

2 Kant usa aquí el predicado objetivo de una manera algo ambigua, pero es posible comprenderlo de la siguiente manera: un auténtico juicio de conocimiento posee validez objetiva en sentido constitutivo, porque el concepto que en aquel se enlaza con una representación dada es determinante del objeto mismo. En cambio, en el juicio teleológico el concepto que se enlaza con la representación dada no es una determinación del objeto, sino solo una regla para reflexionar sobre este. En este sentido, puede decirse que el carácter objetivo del juicio teleológico es meramente regulativo. Un juicio estético, en fin, no es objetivo de ninguna manera, porque solo se ocupa del modo subjetivo de sentir la representación dada en referencia totalmente indeterminada a nuestra facultad de conocimiento. En los tres casos, sin embargo, puede verse que hay algún tipo de referencia a las facultades de conocimiento en general. 
modo de sentir. En efecto, la preeminencia de la belleza natural sobre la artística radica, para Kant, precisamente en esto: en la espontaneidad con que la naturaleza obra impremeditadamente en la formación de cosas bellas ${ }^{3}$, y en el pensamiento consecuente de que lo bello simplemente se dé, esto es, que exista sin fin alguno determinado pero de manera concordante con nuestro sentimiento de placer (cf. Oyarzún 1992, pp. 84-85). Por eso, dice Kant, suponemos un "alma bella (schöne Seele)" en el hombre que abandona con gusto el salón de arte en que la sociedad se entretiene, para volver a lo bello natural y cavilar sin fin a su propósito (cf. $K U \S 42$, AA V. 299-300; tr., p., 210).

En este sentido, es primeramente el sentimiento de la belleza natural y su principio de la conformidad a fin formal y sin fin el que proporciona un concepto de la naturaleza (aunque no un conocimiento objetivo de ella) más amplio que el del mero mecanismo de la causalidad eficiente. El pensamiento de que la naturaleza produce espontáneamente formas adecuadas a nuestra facultad de juzgar $\mathrm{y}$, por tanto, que posee una capacidad artística o técnica en su diversidad particular acorde con lo que supone el entendimiento en su configuración categorial, ese es un pensamiento que solo puede ser ocasionado por el sentimiento de la libre conformidad de imaginación y entendimiento a propósito de las bellas formas.

Así, y de acuerdo con lo proyectado en la Introducción a esta tercera Crítica, el sentimiento de lo bello cumple con uno de los objetivos que allí se planteaban, pues muestra que se da una conmensurabilidad espontánea entre las formas particulares de la naturaleza y nuestras facultades de conocimiento. Esta concordancia (sentida subjetivamente como necesaria) basta, según Kant, para dar cuenta del "mandato" (Geheiss) de la facultad de juzgar de proceder siempre de acuerdo al principio de la conformidad a fin de lo contingente, aunque nunca se pueda probar objetivamente su validez (cf. $K U$, Einleitung, AA V, 188 ss.; tr., p. 99 ss.).

Como señalaba recién, sin embargo, para justificar la aplicación del juicio teleológico a la naturaleza es necesario que algo se nos dé objetivamente y que la misma experiencia de eso dado nos exija un tipo de comprensión distinta a la del mecanismo causal, pues de otro modo el principio de la conformidad a fin no cumpliría ningún papel epistemológicamente relevante. En este punto, el carácter subjetivo de la reflexión -tanto estética como teleológica- no puede hacernos olvidar que en ella siempre está en juego la relación originaria de la receptividad del sujeto con la presentación de algo existente. En el caso del juicio teleológico, Kant sostiene que lo que se nos presenta de tal manera son precisamente los seres vivos u organizados.

En efecto, que en la naturaleza se den fines naturales (Naturzwecke), esto es, objetos en cuyo concepto se encuentre el fundamento de su realidad efectiva, es en principio solo una suposición de la facultad de juzgar reflexionante. Lo único que

3 Por esto, sostiene Kant, la "simplicidad" (Einfalt), que consiste en la "conformidad a fin sin arte", es el "estilo" (Stil) común de la naturaleza y de la moralidad ( $K U$, Allgemeine Anmerkung zur Exposition..., AA V, 275; tr., p. 187 s.). 
justifica, según Kant, la necesidad de aplicar el concepto de fin a la naturaleza misma es la experiencia de ciertos fenómenos cuya explicación causal de acuerdo a leyes meramente mecánicas no sea suficiente para dar cuenta del sentido que nosotros mismos les atribuimos en la experiencia (cf. $K U \S 80, \mathrm{AA} \mathrm{V,} \mathrm{417;} \mathrm{tr.,} \mathrm{p.} \mathrm{345).} \mathrm{Así,} \mathrm{por} \mathrm{ejemplo,}$ en la explicación del mecanismo del ojo y la visión -para tomar uno de los ejemplos preferidos de Kant-, el investigador puede orientar sus indagaciones bajo una suposición regulativa pero altamente eficaz: que el concepto mismo de la visión esté en el fundamento de la causalidad del ojo. Con esta suposición, por cierto, la explicación mecánica no sufre merma alguna, argumenta Kant, porque aplicar la idea de un fin de la naturaleza a este producto en particular es más bien un aliciente para ordenar en un verdadero sistema cohesionado lo que desde un punto de vista mecánico podría ser solo un agregado sin afinidad.

La concepción kantiana de los organismos como fines naturales constituye, pues, una suerte de epistemología de la naciente biología, inspirada en Buffon, Maupertuis y muy especialmente en Blumenbach (cf. Huneman 2008; Lenoir 1980). Quisiera explicar aquí solamente una observación de Kant en este contexto, relevante para el presente argumento.

Según Kant, una propiedad distintiva de los seres vivientes es que poseen fuerza formadora (bildende Kraft) y no únicamente fuerza motriz (bewegende Kraft). En este sentido, un organismo no es solo un ser organizado (un todo que es a la vez causa y efecto de las partes), sino también un ser "organizante de sí mismo”, es decir, capaz de producir una organización semejante a partir de materias desprovistas de aquella organización ( $K U \S 65$, AA V, 373 s.; tr., p. 304 s.). Dado el tipo peculiar de causalidad que aquí se piensa a propósito de los organismos, a saber, una tal que no solo avanza en una serie descendente de causas y efectos (causalidad mecánica), sino que también avanza en sentido ascendente de modo tal que un efecto puede ser considerado a la vez como causa de la cosa de la cual es efecto (causalidad final), el principio explicativo de la causalidad mecánica no es capaz de aclarar tales fenómenos en su particularidad, sostiene ahí mismo Kant, y se hace necesario recurrir a la máxima de la conformidad a fin objetiva.

En este sentido, el principio de la conformidad a fin objetiva de la naturaleza sigue siendo una máxima heurística, una regla de comprensión, pero es también expresión de una experiencia particular del sujeto racional finito con ocasión de ciertos fenómenos. En efecto, si la explicación mecánica llega alguna vez al límite de su potencia y el investigador recurre entonces a la idea de un fin natural, no es esta idea la que pone un límite a tal explicación, sino que es la limitación misma de la explicación mecánica respecto del fenómeno en cuestión la que hace necesaria la introducción de un concepto distinto de causalidad, aunque solo sea para reflexionar adecuadamente a propósito del fenómeno en particular (cf. Breitenbach 2006).

Según Kant, solo los fenómenos orgánicos nos imponen esta necesidad de pensar teleológicamente. En cambio, con ocasión de la observación de una piedra, por ejemplo, que bien puede ser usada para ciertos fines externos a ella, no se requiere en absoluto de una máxima teleológica (cf. 1. Einleitung $K U$, AA XX, 240 s.; tr., p. 60). 
Sin embargo, como adelantaba hace un momento, Kant niega expresamente que el principio de la conformidad a fin de la naturaleza incluya el concepto determinado de una intención o propósito en la naturaleza misma. La técnica o arte de la naturaleza -que es la forma que adopta el principio de la conformidad a fin en el juicio teleológico-, entonces, tiene que ser concebida, consecuentemente, como "espontánea" (1. Einleitung KU, AA XX, 235; tr., p. 55), es decir, como conforme a fin, pero sin intención determinada, para decirlo destacando el paralelo con la fórmula del juicio reflexionante estético: la conformidad a fin sin fin.

Pues bien, de estas consideraciones preliminares se desprenden dos conclusiones que me interesa destacar.

1) En primer lugar, que el juicio teleológico supone ya un concepto peculiar del objeto para ejercer su reflexión, esto es, piensa el objeto de acuerdo al concepto racional de un fin que estaría en el fundamento de la producción de tal objeto. Por esto puede decir Kant que la facultad de juzgar teleológica no remite por sí misma a un principio a priori particular: ella pertenece finalmente al interés especulativo y es del dominio de la facultad de conocer. Pero esto quiere decir a su vez -y esto es lo que ahora quisiera enfatizar- que el principio de la conformidad a fin que rige la reflexión del juicio teleológico tiene que estar preparado ya por el principio de la conformidad a fin sin fin, cuyo ejemplo paradigmático es el del juicio estético sobre lo bello, y que aquel, por tanto, es en el fondo incomprensible sin este. El juicio estético, en efecto, prepara el concepto puro de fin, sin determinarlo de ninguna manera (ni por un concepto del entendimiento, ni por uno de la razón), y solo por eso puede luego el juicio teleológico intentar aplicarlo a la naturaleza en cuanto fin natural. Si la crítica del juicio estético no hubiera descubierto originalmente el principio de la conformidad a fin, reconoce el mismo Kant, la teleología no ocuparía lugar alguno en la crítica (cf. 1. Einleitung $K U$, AA XX, 244; tr. p. 63).

2) En segundo lugar, Kant señala que la reflexión teleológica no se dirige ya a la forma contingente de las cosas en su diversidad particular (como se hace en la reflexión estética), sino, como se ha visto, a la materia de la naturaleza en cuanto esta puede ser pensada a su vez como conforme a fin. En este sentido, Kant intentará pensar la naturaleza misma como un sistema de fines, esto es, como una totalidad que se organiza espontáneamente de acuerdo con relaciones finales. Con todo, modificar de esta manera el concepto de naturaleza implica también un problema de fondo dentro del criticismo. En efecto, la dualidad misma de materia y forma y la distinción fundamental entre receptividad y espontaneidad-que están en las bases de todo el proyecto crítico-, sufren con esto, ahora sí, una modificación significativa. En efecto, la doctrina de la primera Crítica establece que solo hay objetos de conocimiento cuando la materia de la sensación, conformada espacial y temporalmente, es referida a la apercepción trascendental y a su configuración categorial. Imaginación y entendimiento, entonces, actúan espontáneamente en la formación de los objetos. La noción clave de experiencia posible, que articula toda la primera Crítica, apunta precisamente a la delimitación de las condiciones formales de posibilidad de los objetos. ¿Qué pasa, entonces, con la existencia 
material misma de tales objetos? Para Kant, la categoría modal de existencia solo indica esto: que una representación concuerda con las condiciones materiales de la experiencia (cf. $K r V$, A 218 / B 265-266), es decir, que algo sencillamente se da.

Para una explicación mecánica de la naturaleza esto es, sin duda, suficiente, pues queda probado que todo fenómeno, desde el punto de vista de su forma en general, está necesariamente sometido a las leyes universales del entendimiento, una de las cuales es la ley de causalidad. Pero, como Kant destaca ahora, también lo particular de la naturaleza, sus formas contingentes y su materia misma han de ser de alguna manera aptas para acoger los intereses del entendimiento y de la razón, y esto de modo totalmente espontáneo.

El principio de la conformidad a fin sin fin del juicio estético da ya una primera muestra de esa aptitud espontánea de la naturaleza con ocasión de las formas bellas. En el plano estético, sin embargo, solo estábamos autorizados a decir que éramos nosotros los que acogíamos favorablemente a la naturaleza cuando juzgábamos algo como subjetivamente conforme a fin. Y quedaba entonces abierta la pregunta por la aptitud de la naturaleza misma, en su materia, para producir espontáneamente fenómenos conformes a fin, dada, precisamente, su radical contingencia.

Si Kant ha logrado demostrar esto último, entonces se entiende que, desde una perspectiva teleológica, uno pueda reconsiderar a su vez el juicio estético y pensar que era la naturaleza misma la que, en el fondo, nos concedía un favor al presentarse como placentera en sus productos, como señala Kant (cf. $K U$ § 67, AA V, 380; tr., p. 311), lo que implica que habría una suerte de aptitud para la forma en la materia misma. Con esto, sin embargo, los claros límites establecidos anteriormente entre materia y forma y entre receptividad y espontaneidad comienzan ahora, al menos en cierto modo, a desdibujarse ${ }^{4}$.

El esfuerzo de Kant por ahondar en estas nuevas indagaciones trascendentales sin traspasar los límites asegurados en las dos primeras Críticas es, sin embargo, colosal. Cada vez que da un paso adelante en la consideración de la espontaneidad de la naturaleza o de esta como un sistema organizado, nos recuerda que aquí solo se trata de nuestro modo de reflexionar con ocasión de ciertos fenómenos, y entonces parece que todo el edificio crítico quedara intacto con tales avances (cf. Zammito 2008). Pero no se puede desconocer que los nuevos conceptos que Kant introduce a propósito de esta reflexión implican, por decir lo menos, una revisión de las doctrinas ya establecidas.

4 La coincidencia, al menos parcial, de esta suerte de paradoja con el tratamiento husserliano de la "síntesis pasiva" es interesante. Lebrun (1970) ha destacado también la semejanza del proyecto kantiano expuesto en las dos introducciones a la Crítica de la facultad de juzgar y la investigación fenomenológica de la experiencia pre-objetiva (p. 268 s.). Sin embargo, las interpretaciones que hace Husserl de Kant rara vez le hacen justicia, aun cuando son patentes las coincidencias en muchos respectos.. 
Esto es particularmente evidente en el tratamiento kantiano del concepto de $f i n$, que era considerado hasta ahora un concepto de origen práctico totalmente ajeno a las categorías del entendimiento que rigen nuestro conocimiento de la naturaleza, y que aquí, sin embargo, Kant introduce precisamente a propósito de nuestra experiencia del mundo natural.

Como ya se ha visto, Kant reconoce, desde un principio, que no tenemos ningún derecho a introducir simplemente y sin justificación precisa las causas finales en la explicación natural. De hecho, la contingencia de la naturaleza y de sus productos se hace evidente precisamente por esto: lo que ella ha formado de acuerdo al mero mecanismo pudo haberse formado de muchas otras maneras, y no cabe determinar ningún fundamento en la naturaleza misma (considerada como el conjunto de los fenómenos categorialmente determinados) que permita sostener que ella procede de acuerdo con otra causalidad, como, por ejemplo, la final (cf. $K U \S \S 61,75$, AA V, 360 , 398 s.; tr., pp. 292, 328).

Kant ha intentado mostrar, sin embargo, que sí tenemos derecho a juzgar de acuerdo con el principio de la finalidad -y esto incluso de modo necesario- cuando la explicación causal llega a su límite ${ }^{5}$. Este punto es crucial porque -se dirá- el propio Kant ya había establecido en su primera Crítica que todos los objetos están sometidos a las leyes mecánicas, pues ellos solo son posibles según estas. Pero entonces hay que recordar un aspecto de esta doctrina en el que ya he insistido anteriormente: es solo la naturaleza formaliter spectata la que está sometida necesariamente a los principios del entendimiento; su materia, en cambio, e incluso sus formas particulares, siempre conllevan un elemento irreductible al poder del entendimiento, elemento que no puede ser totalmente anticipado por la capacidad conformadora del sujeto ${ }^{6}$.

Kant insiste en este punto al distinguir expresamente entre la conformidad a fin material de la naturaleza - de la que se trata aquí- y el tipo de conformidad a fin intelectual, que cabe encontrar, por ejemplo, en las figuras geométricas y los números: estas últimas son solo representaciones en nosotros, y pueden reducirse en último término a las formas de la intuición pertenecientes al sujeto mismo; en el primer caso, en cambio, debemos pensar un fin especial fuera de nosotros, porque se trata de una concordancia espontánea que no es producida por el sujeto, sino -así lo pensamos, sostiene Kant (cf. $K U$ § 62, AA V, 363 s.; tr., p. 296)- por la naturaleza misma (cf. Giordanetti 2008).

5 De un modo similar argumentaba Kant en su opúsculo de 1788 Sobre el uso de principios teleológicos en la filosofía (cf. Teleologische Principien, AA VIII, especialmente 180 ss.).

6 Por eso tampoco hay que confundir este tratamiento del problema de la materia con el que Kant ya había desarrollado unos pocos años antes es sus Principios metafisicos de la ciencia de la naturaleza, pues en esta obra, Kant aborda el concepto de materia únicamente desde un punto de vista puro y sin salirse del marco de la materia inerte provista únicamente de "fuerza motriz" (MAN, AA IV, 497 ss.). 
Aquí nos encontramos, pues, con ese pensamiento que Kant había caracterizado anteriormente como un indicio de la disposición moral del hombre a propósito de la contemplación de lo bello, a saber, el pensamiento de que la naturaleza ha producido por sí misma, de manera espontánea, la belleza para nosotros. La noción de fin que aparecía ahí totalmente indeterminada en ese para nosotros, y que solo era sentida estéticamente en nuestro modo de acoger lo particular de la naturaleza, es ahora indagada en su posible fundamento trascendental: algo en la naturaleza se presenta, más allá de su forma en nosotros, como conforme a fin.

\section{Referencias bibliográficas}

1. Obras de Kant

1. Einleitung KU: Erste Einleitung in die Kritik der Urteilskraft. AA XX, 193-251 (Primera versión de la Introducción a la Crítica de la facultad de juzgar. "La filosofia como un sistema”. Tr. de P. Oyarzún. En I. Kant, Crítica de la facultad de juzgar (pp. 23-70). Caracas: Monte Ávila, 1992).

AA: Kant's gesammelte Schriften. Bd. I-XXII, hrsg. von der Preussischen Akademie der Wissenschaften, Bd. XXIII von der Deutschen Akademie der Wissenschaften zu Berlin, ab Bd. XXIV von der Akademie der Wissenschaften zu Göttingen. Berlin: 1902 ss.

Beweisgrund: Der einzig mögliche Beweisgrund zu einer Demonstration des Daseins Gottes. AA II, 63-163 (El único fundamento posible de una demostración de la existencia de Dios. Tr. de J. M. Quintana. Barcelona : Zeus, 1972).

GMS: Grundlegung zur Metaphysik der Sitten. AA IV, 385-463 (Fundamentación de la metafísica de las costumbres (14 ${ }^{\mathrm{a}} \mathrm{ed}$.). Tr. de M. García Morente y rev. de L. Martínez de Velasco. Madrid: Espasa Calpe, 1999).

$\mathrm{KrV}$ : Kritik der reinen Vernunft. Nach ersten und zweiten Originalausgabe, hrsg. von Jens Timmermann. Hamburg: F. Meiner, 1998. También en AA III, 1-552; IV, 1-252 (Crítica de la razón pura. Tr. de P. Ribas. Madrid: Alfaguara, 1978).

KU: Kritik der Urteilskraft. AA V, 165-485 (Crítica de la facultad de juzgar. Tr. de P. Oyarzún. Caracas: Monte Ávila, 1992).

MAN: Metaphysische Anfangsgründe der Naturwissenschaft. AA IV, 465-565 (Principios metafísicos de la ciencia de la naturaleza. Tr. de C. Másmela. Madrid: Alianza, 1989).

Teleologische Principien: Über den Gebrauch teleologischer Principien in der Philosophie. AA VIII, 157-184.

Theorie des Himmels: Allgemeine Naturgeschichte und Theorie des Himmels, oder Versuch von der Verfassung und dem mechanischen Ursprunge des ganzen Weltgebäudes, nach Newtonischen Grundsätzen abgehandelt. AA I, 215-368 (Historia natural y teoría del cielo. Tr. de J. Lunqt. Buenos Aires: Juárez, 1969). 
2. Bibliografía secundaria

Allison, H. (1991), “Kant's antinomy of teleological judgment”. The Southern Journal of Philosophy, XXX (Supplement): 25-42.

Breitenbach, A. (2006), "Mechanical explanation of nature and its limits in Kant's Critique of judgment". Studies in History and Philosophy of Biological and Biomedical Sciences. 37: 694-711.

Butts, R. E. (1984), Kant and the double government methodology. Dordrecht: D. Reidel.

Ginsborg, H. (2004), "Two kinds of mechanical inexplicability in Kant and Aristotle". Journal of the History of Philosophy. 42: 33-65.

Giordanetti, P. (2008), "Objektive Zweckmässigkeit, objektive und formale Zweckmässigkeit, relative Zweckmässigkeit (§§ 61-63).” En O. Höffe (ed.), Immanuel Kant. Kritik der Urteilskraft. Berlin: Akademie, pp. 211-222.

Guyer, P. (ed.) (1992), The Cambridge Companion to Kant. Cambridge: Cambridge University Press.

Hume, D. (S-B), Enquiries concerning human understanding and concerning the principles of morals. L. A. Selby-Bigge (ed.). Oxford: Clarendon, 1975 (Investigación sobre el conocimiento humano. Tr. de J. de Salas Ortueta). Madrid: Alianza, 2001.

Huneman, Ph. (2008), Métaphysique et biologie. Kant et la constitution du concept d'organisme. Paris: Kimé.

Lebrun, G. (1970), Kant et la fin de la métaphysique. Essai sur la 'Critique de la faculté de Juger'. Paris: A. Colin.

Lenoir, T. (1980), "Kant, Blumenbach, and vital materialism in German biology." Isis. 71 (1): 77-108.

(1982), The strategy of life. Teleology and mechanics in nineteenth-century German biology. Dordrecht: Reidel.

McLaughlin, P. (1990), Kant's critique of teleology in biological explanation. Antinomy and teleology. Lewiston: E. Mellen.

Molina, E. (2007), "Juicio, ley y aplicación. Un problema central de la Crítica de la facultad de juzgar". Anuario Filosófico. XL/3: 673-695.

Oyarzún, P. (1992), "Imitación y expresión. Sobre la teoría kantiana del arte”. En V. Rohden (ed.), 200 anos da Crítica da facultade do juízo de Kant. Porto Alegre: Editora da Universidade, pp. 83-105.

Watkins, E. (2008), "Die Antinomie der teleologischen Urteilskraft und Kants Ablehnung alternativer Teleologien ( $\S 69-71$ und $\S \S 72-73)$ )". En O. Höffe (ed.), Immanuel Kant. Kritik der Urteilskraft. Berlin: Akademie, pp. 241-258.

Zammito, J. (2008), "Kant et la téléologie". En Bouton, Brugère et Lavaud (eds.), L'année 1790. Kant. Critique de la faculté de juger. Beauté, vie, liberté. Paris: Vrin, (pp. 45-54).

Zuckert, R. (2007), Kant on beauty and biology. An Interpretation of the Critique of Judgment. Cambridge: Cambridge University Press. 